\title{
Liquidity Contagion The Emerging Sovereign Debt Markets example
}

\author{
Serge Darolles* \\ Jérémy Dudek ${ }^{\dagger}$ \\ Gaëlle Le Fol ${ }^{\ddagger}$
}

September 19, 2012

\begin{abstract}
Financial markets are today so interconnected that they are fragile to contagion. Massive investment funds with very short horizons in -and out- flows can generate contagion effects between markets. Since 2010, investors are willing to get a liquid exposure to the EM sovereign debt. As a consequence, some asset management firms started to propose products to track the performance of this asset class. However in that case, the fund manager faces a mismatch of liquidity between assets and liabilities and needs some tools to manage the liquidity of his investments. The main contribution of this paper is the analysis of contagion, looking at common market liquidity problems to detect funding liquidity problems. Indeed, the main risk for an asset manager is to get stuck with unwanted sovereign debt due to a dry-up of market liquidity. We use the Credit Default Swap bond spread basis as a liquidity measure for the sovereign debt market. Moreover, we distinguish interdependence and pure contagion using a state space model with a time-varying volatility specification, and we apply it to both returns and liquidity indicators.
\end{abstract}

JEL classification: G01, G15, C01, C32

Key words: Emerging Markets, Sovereign Debt Market, Liquidity Risk Management, Liquidity, Contagion Effects, Regime Switching models.

\footnotetext{
*Université Paris Dauphine - DRM and CREST-INSEE, France, serge.darolles@ensae.fr

${ }^{\dagger}$ CREST-INSEE and Université Paris Dauphine - DRM, France, jeremy.dudek@ensae.fr

${ }^{\ddagger}$ Université Paris Dauphine - DRM and CREST-INSEE, France, gaelle.le_fol@dauphine.fr

The authors gratefully acknowledge financial support of the chair Amundi/Dauphine Fundation "Asset Management". We thank Monica Billio, Dale Rosenthal, Sessi Tokpavi, the participants of the $5^{\text {th }}$ International conference on Computational and Financial Econometrics in London, the $4^{t h}$ Annual Conference on Hedge Funds in Paris, the $66^{\text {th }}$ European Meeting of the Econometric Society in Malaga, the finance department seminar, New York University-STERN School of Business for useful comments. Dudek gratefully acknowledges Viral Acharya for sponsoring NYU visiting position in 2012.
} 


\section{Introduction}

Investors need funding to trade securities. When the funding liquidity conditions are bad, they cannot easily access to capitals which impair their trade capacities. If many investors are concerned by such a funding liquidity problem, trading is slowing down which reduces market liquidity. As investors' funding depends on assets' market liquidity, market liquidity and funding liquidity problems can be mutually reinforced leading to liquidity spirals [see e.g., Gromb and Vayanos (2002), Morris and Shin (2004), Brunnermeier and Pedersen (2009), Menkveld and Wang (2011)]. During such troublesome periods, like in 2008, the crisis has spread accross assets and markets as many investors were seeking for liquidity creating a huge liquidity contagion. This paper analyzes this phenomena looking at common market liquidity problems to detect funding liquidity problems.

While traders are funded by banks, fund managers are funded directly by investors. Indeed, we can distinguish the liability part of the fund which consists of the investor's inflows and the asset part which contains the fund's holdings. Thus, the fund managers faces a liquidity mismatch between the asset and the liability sides. On the one hand, investors wanted more and more liquid exposures. Thus, the liability part's liquidity is contractually defined and usually really high. On the other hand, for the asset side of the fund, its liquidity is determined by the nature of the investments and usually lower than that of liabilities. As the behavior of these funding providers can largely differ, the fund managers need to monitor this liquidity mismatch. Increasing the cash balance of the fund is one way to minimize this problem. However, if the amount of cash is too large, it will be idle and not producing. Conversely, if it is too small, the fund will still be exposed to the liquidity risk, so that it would be useless.

Considering the perspective of a fund manager, we have to deal with liquidity constraints defined by the fund. However, the fund manager should build a portfolio to benefit from the diversification principle. Thus, the main fear for the manager is a re-correlation of the assets. Indeed, this phenomena may lead to the cancelation of the diversification benefits and increases the risk. We consider in this paper the example of index funds invested on Emerging Sovereign

Brunnermeier and Pedersen (2009) distinguish funding liquidity from market liquidity. The first characterizes the possibility for traders to find funds while the second characterizes the ease to trade an asset on the market. Traders provide market liquidity and their ability to do so depends on their capacity of funding. Funding liquidity is binding market liquidity as traders can only provide liquidity if they can access to fundings. 
Debt Markets. The contribution of this paper is twofold: firstly, we explore a measure of liquidity for the sovereign debt market and secondly, we propose a method to identify contagions effects. Thus, we study the liquidity in a funding perspective analyzing the re-correlation of market liquidity indicators.

The term of Emerging Markets (EM hereafter) appears for the first time in 1981. Since then the World Bank classifies as EM any markets meeting at least one of the following criteria: (i) being located in a low or middle-income economy as defined by the World Bank, (ii) not exhibiting financial depth; the ratio of the country's market capitalization to its GDP is low , (iii) existence of broad based discriminatory controls for non-domiciled investors, or (iv) being characterized by a lack of transparency, depth, market regulation, and operational efficiency. The creation of emerging markets is motivated by the need of developing countries to raise capital to finance their growth. Before the 2000's developing countries borrowed either from commercial banks or from foreign governments multilateral lenders (International Monetary Fund or World Bank). Capital flows to emerging markets increased dramatically. Commercial bank debt that was the dominant source of foreign capital has been replaced by portfolio flows and foreign direct investment [Bekaert and Harvey (2003)].

EM are today considered as an asset class per se by many investors. Emerging economies have passed an important stress test during the period 2008-2009 and are now the key drivers for global growth of the world economy. As pointed out by the JP Morgan recent study, "Potential growth rates for emerging economies of $5.8 \%$ now overshadow potential growth of only $1.6 \%$ for advanced economies". This explains why these markets are associated with very interesting investment opportunities for any investor seeking both returns enhancement and diversification. Inflows into EM have reached a record of US\$70 billion in 2010 and will continue to grow as EM yields stay attractive in the context of current global bond markets. Also interesting to notice, the proportion of EM sovereign debt in local currency now account for around $80 \%$ of the total EM sovereign debt. As a consequence, any simple mean-variance portfolio optimization suggests a high allocation to EM debt. Different client surveys made by banks show an increase

World Bank define low GDP as less than 755 USD per capita.

fixed income and equity.

JP Morgan Securities, Emerging Markets Research, EM Moves into the Mainstream as an Asset Class, November 23, 2010 
in EM debt allocation from around $20 \%$ in 2009 to around $25 \%$ one year later. Therefore, EM investments must be carefully analyzed. They suffer from additional risk, such as liquidity risk and, in some cases, systemic risk, that are not taken into account in the basic mean-variance approach.

Coming back to the example of a fund manager tracking the performances of Emerging Markets, the figure (1) shows that a funding liquidity problem can largely impact the returns of a fund. Indeed, we see that the performances of two different index funds tracking the JPMorgan BGI-EM Index largely differ in October 2008. The best of them (in light gray) experienced 800 millions outflows while the worst of them (in dark gray) known 1400 millions outflows. Relatively to the size of the fund, the second one exposes the difficulty that the managers have to maintain their performances especially when liquidity is scarce.

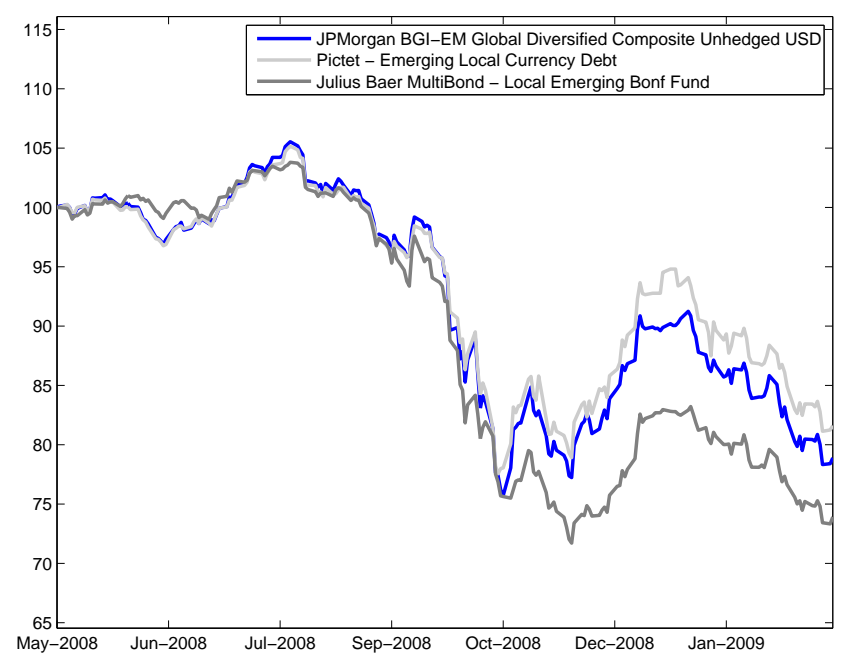

Figure 1 - Both index and funds are expressed in USD. The data are from May 2008 to February 2009.

Despite the large number of liquidity measures available measuring liquidity may remain a difficult task. In fact, many liquidity measures require the use of high-frequency transactions and quotes data, which may not be available for some markets and even more so for emerging markets. However, in most cases, Goyenko et al. (2009) show that their performances are not better than the effective or realized bid-ask spread. Moreover, the weak availability of data for Emerging Markets encourages us to focus on liquidity measures that are able to be computed only with price data. There exists few measures based of daily price data. Roll (1984) develops

Aitken and Winn (1997) report more than 68 measures for market liquidity. 
an implicit measure of the effective bid-ask spread based on the serial covariance of daily price changes. Hasbrouck (2004) uses a Bayesian estimation approach to estimate the Roll model and proposes a Gibbs measure of liquidity. Lesmond et al. (1999) use the proportion of zero return days as a proxy for liquidity. As Levy (2009), we use the CDS Bond Spread basis as a liquidity indicator. It has the main advantage to be available for Emerging Sovereign Debt markets being only based on price data. Moreover, we use low frequency data allowing the study of longer periods and the computation of estimation models for contagion.

Financial contagion is definitely a burning issue and a major concern in the academic literature, particularly since the end of 1990's. Indeed, during the past 20 years, financial markets became more and more interconnected and, as a consequence, more and more fragile to contagion. For example, massive investment funds' in- and out- flows on very short horizons can be a source of contagion effects. Since the summer 2011, we observe some contagion phenomena that play a crucial role in exacerbating the sovereign debt problems in the euro area. But before this, the issue of financial contagion was mainly concerning EM with the Asian crisis 1997-1998, the Russian crisis 1998, the Brazilian crisis 1999, Turkish crisis in 2001 and Argentinean crisis in 2002. However, every fund manager that faces a liquidity mismatch or a risk constraint, as it is the case in the industry, needs a model taking into account the possible re-correlation or contagion phenomena. Standard linear models such Markowitz approach can not tackle these problems. Thus, one need to consider non-linear model not only based on the first two moments of the return's distribution.

In this paper, we use an arbitrage relation to extract a liquidity measure of the sovereign debt market that solely relies on price data. Based on this liquidity measure, we propose a pure contagion effects identifying tool. Such a tool allows us to study if there exist pure contagion effects on EM Sovereign Debt markets and we investigate the re-correlation phenomena that the sovereign debt market experiences during liquidity turmoils using a dynamic model based on a regime switching. Our results show similar regimes between the CDS market and our liquidity indicator, the CDS Bond Spread Basis. From Garleanu and Pedersen (2009), Fontana and Scheicher (2010) and Bai and Collin-Dufresne (2011), we know that the basis is related to the credit risk of a bond. In other words, a larger deviation from parity is found for lower rated bonds because it is more costly to finance the arbitrage trade. In this paper, we show that when 
the correlations between CDS are high and investors are funding constrained, the basis deviates from parity. Namely, the re-correlation problem is even bigger during crisis periods especially when liquidity problem occurs. Thus, the fund manager has to prevent this kind of event.

The remainder of the paper is organized as follows. Section 2 introduces the liquidity measure and the regime switching dynamic correlation model to identify pure contagion events. Section 3 describes data and presents descriptive statistics and graphic results on the liquidity measure. Section 4 analyzes the dynamic of the smoothed probabilities showing the behavior of the sovereign bonds or credit default swaps and their liquidity. Section 5 concludes.

\section{Liquidity measure and contagion model}

In this section, we explore the CDS Bond Spread Basis and we focus on its ability for estimating the liquidity of the sovereign debt markets. Then, we expose how to compute it and we suggest how to correct it from the difference between issuance currencies. Indeed, we have to be able to compare CDS premium denominated in US dollars with sovereign debt yields issued in local currencies. In a second part, we expose contagion's definitions and the Regime Switching Dynamic Correlation model (RSDC hereafter) to detect financial contagion effects. This model gives a simple interpretation of correlation switches, corresponding exactly to the most used contagion's definition.

\subsection{CDS Bond Spread Basis}

There exists many determinants of liquidity on emerging sovereign debt markets. First of all, the size of the market is preponderant at the beginning of 2000s, when emerging markets were small. The increase of liquidity between 2005 and 2007 is partly due to the importance of inflows. However, the investor base has to stay as large as possible to guarantee market liquidity. This is the problem for Asia at the beginning of 2000's years. Nevertheless, the absence or inadequacy of hedging tools makes the market illiquid. Once again, this is the case in emerging markets early in 2000. Moreover, the valuation of the bond to its historical cost rather than its market value induces investors to keep their bonds to maturity. Thus, the secondary market is less liquid. These facts are common to all emerging markets that, at the start of their growth suffered from 
not being sufficiently developed relatively to the size of the inflows.

CDS were created in 1994 by J.P Morgan \& CO. Since its creation the CDS market is rose until 2008 and has stagnated since. CDS became in a few years a standardized financial product used by most of the market major participants (banks, hedge funds, mutual funds...). Nowadays, it is one of the most popular tool for transferring credit risk. The CDS contract is defined as a bilateral contract that provides protection on the par value of a specified reference asset. The protection buyer pays a periodic fixed fee or a one-off premium to a protection seller. In return, the seller will make a payment on the occurrence of a specified credit event [Choudhry (2006), Mengle (2007)]. Then, CDS provides to buyer a protection against the risk of default by borrowers, named the entities. The default, also named credit event is contractually defined by the two parties and could be bankruptcy, failure to make a schedule payment, obligation default, debt moratorium, financial or debt restructuring and credit downgrade. This is important to precise that rating agencies have not influence in triggering CDS. Their actions may, but not need, taken into account. The protection buyer has to pay an amount of fees (also named CDS premium or CDS spread) to protection seller and receives a payoff if the underlying bond experiences a credit event. At the deal inception, the two parts define which kind of settlement they want. The CDS contract could be settled in one of two ways: cash or physical settlement. Most of the time, contracts are physically settled (about 75-85\%). Although the CDS contract has a given maturity, it may terminate earlier if a credit event occurs. In this case, the protection seller has to pay an amount called the protection leg.

The basis is nothing else but correcting the CDS from the sovereign bond (CDS bond spread basis). This is a way to cancel out the global macro effects when analyzing the commonality of sovereign risk. In other words, we focus on the long term liquidity. The basis is defined as the difference between the asset itself and its synthetic version. The no arbitrage theory of pricing CDS implies that the basis should be zero. However, in practice it is almost never the case. This is a result of a combination of factors. Indeed, the level of the basis could fluctuate for many reasons that could be split into two categories: technical and market factors. We mainly find in the technical factors the delivery option and counterparty risk. To characterize the first,

The main part of CDS are documented using the 2003 ISDA Credit Derivatives Definitions, as supplemented by the July 2009 Supplement. 
we have to define what deliverable options means. CDS contracts usually allow buyer and seller to agree on a panel of alternative assets that the buyer can deliver in case of a credit event. However, this allows to the buyer to deliver the cheapest obligation that he possesses in his eligible basket of assets. However, this option does not add value systematically even in the case of sovereign debt market. As we see in Ammer and Cai (2007), the CTD option could be valuable for the emerging sovereign debt market. However, our model is based on the fact that there exists some frictions interfering with exact arbitrage between CDS and bonds particularly the liquidity of the sovereign debt market. In this context, it becomes really difficult to model and evaluate the CTD option. Indeed, Ammer and Cai (2007) propose to measure the spread part that could be attributed to CTD option. Their model requires two strong assumptions allowing to measure the CTD option: the recovery rate is independent of time-to-default and the CTD option is the only friction. However, this is empirically proved that market liquidity is one of the main friction interfering in the arbitrage relation between the CDS premium and the bond yield spread over the risk free rate. Moreover, the recovery rate is time dependent given that it corresponds to the recovery rate of the underlying bond. Then, as the CTD option, although valuable, is sometimes null we neglect it in our model to focus on the market liquidity. The second is the counterparty risk. On the one hand, the protection seller can default and do not settle the protection buyer in case of a credit event. On the other hand, the buyer can also default and stop paying the CDS premium to the seller. However, some mechanisms like counterparty clearing system allow to reduce these risks (almost half of CDS are treated by clearing). Moreover, as we see on Levy (2009), if the default probability of the underlying bond and the default probability of the counterparty are not correlated, the two effects cancel each other out. Furthermore, counterparty risk is a joint event of two defaults. Thus, the excess premium associated is weighted by a product of two probabilities and should be really small, or negligible. Our aim being the analysis of the dynamic of the emerging market liquidity, we neglect the counterparty risk. Indeed, based on a demonstration proposed by Levy (2009), we focus on the liquidity premium induced by the movements of the basis on emerging markets.

CDS includes two legs corresponding to the premium payments and the default payment. The pricing of a CDS depends on the recovery amount (a recovery rate of par value and accrued interest). Following Duffie (1999) or Hull and White (2000) they expose two approaches for the 
CDS Spread pricing. The first that we call "no arbitrage" approach follows the idea that an investor can buy a CDS and the underlying bond to replicate the risk free rate. The second is based on a reduced-form model with random stopping time. We use the first one. Indeed, buying a risky bond and its CDS with the same maturity allow to the investor to eliminate the default risks associated with the bond. Assuming that there is no arbitrage opportunities, this portfolio should be equal to the value of the risk free bond with the same maturity. As in Zhu (2006), we price CDS premiums and Bonds separately. Then, we construct a portfolio that replicate the CDS contract and we obtain the CDS Spread Basis. In this context we assume a risk neutral world with three assets: a risk-free bond, a risky bond and a CDS contract.

Following Levy (2009), under the risk neutral valuation, we note the CDS premium, $b$ satisfies:

$$
\sum_{t=1}^{T} b e^{-r t} F(t)=\int_{0}^{T}\left(100-R V_{t}\right) e^{-r t} f(t) d t,
$$

where $T$ is the number of times till maturity or default, $r$ is the risk-free rate, $R V_{t}$ is the recovery value at time $t, f(t)$ is the probability of default at time $t$ and $F(t)$ is the survival probability. The left hand side is called the Premium leg and the right hand side is called the Insurance leg.

The value of the risky bond is expressed as:

$$
Y=\sum_{t=1}^{T} C e^{-r t} F(t)+100 e^{-r T} F(T)+\int_{0}^{T} R V_{t} e^{-r t} f(t) d t,
$$

where $C$ is the fixed coupon paid for each period.

And the value of a risk-free bond at risk-free rate $r$ is expressed as:

$$
100=\sum_{t=1}^{T} r e^{-r t}+100 e^{-r T} .
$$

Then, we construct a portfolio that shorts the risky bond and buys the risk free bond subtracting (2) to (3), we obtain:

$F(t)=1-\int_{0}^{t} f(x) d x$ 


$$
100-Y=\sum_{t=1}^{T} r e^{-r t}+100 e^{-r T}-\sum_{t=1}^{T} C e^{-r t} F(t)-100 e^{-r T} F(T)-\int_{0}^{T} R V_{t} e^{-r t} f(t) d t .
$$

But if we modify the risk-free bond equation to include default probability, we obtain:

$$
100=\sum_{t=1}^{T} r e^{-r t} F(t)+100 e^{-r T} F(T)+\int_{0}^{T} 100 e^{-r t} f(t) d t .
$$

Then, the value of our portfolio is :

$$
100-Y=\sum_{t=1}^{T}(r-C) e^{-r t} F(t)+\int_{0}^{T}\left(100-R V_{t}\right) e^{-r t} f(t) d t .
$$

However, rearranging with equation (3), we obtain:

$$
100-Y=\sum_{t=1}^{T}(b+r-C) e^{-r t} F(t)
$$

Finally, the CDS Bond Spread Basis is expressed as:

$$
b+(r-C)=\frac{100-Y}{\sum_{t=1}^{T} e^{-r t} F(t)}
$$

The CDS Spread Basis is then equal to zero since the risky bond is traded at par, ie $Y=100$. Moreover, the fixed coupon of a par bond is equal to the bond's yield to maturity $(y=C)$ and we have:

$$
b-(y-r)=0
$$

Moreover, assuming that there are two traders: (i) with high liquidity (h) and (ii) with low liquidity (1). Note $b_{i}$ the CDS premium fair price for the trader $i, i=l, h, \tilde{S}$, the market price for this CDS and $p_{i}$ the probability to find in the first search a trader who are of type $i$. Then, we know that a trader who have liquidity problems, should pay an additional holding cost. Then, from equation (3) we obtain: 


$$
\begin{aligned}
\sum_{t=1}^{T} b_{h} e^{-r t} F(t) & =\int_{0}^{T}\left(100-R V_{t}\right) e^{-r t} f(t) d t & & \text { for high liquidity traders } \\
\sum_{t=1}^{T} b_{l} e^{-(r+d) t} F(t) & =\int_{0}^{T}\left(100-R V_{t}\right) e^{-(r+d) t} f(t) d t & & \text { for low liquidity traders }
\end{aligned}
$$

where $d$ is the additional holding cost.

Then, from these two equations we can extract the CDS premium for each type of traders as:

$$
\begin{array}{cc}
b_{h}=\frac{\int_{0}^{T}\left(100-R V_{t}\right) e^{-r t} f(t) d t}{\sum_{t=1}^{T} e^{-r t} F(t)} & \text { for high liquidity traders } \\
b_{l}=\frac{\int_{0}^{T}\left(100-R V_{t}\right) e^{-(r+d) t} f(t) d t}{\sum_{t=1}^{T} e^{-(r+d) t} F(t)} & \text { for low liquidity traders }
\end{array}
$$

Obviously, trade occurs only if $b_{h}<\tilde{b}<b_{l}$. Moreover, introducing the value of search process $V$, the trader has to be indifferent between searching alone or buying at a market maker. Then:

$$
V=p_{h} b_{h}+p_{l}(V+C)=\frac{p_{h} b_{h}+C p_{l}}{1-p_{l}}
$$

where $C$ is the search cost.

Then, we obtain the market price $\tilde{b}$ that is equal to:

$$
\tilde{b}=V=b_{h}+\frac{C p_{l}}{1-p_{l}}
$$

with $\frac{C p_{l}}{1-p_{l}}$ is the additional spread for the asset (CDS and bond that we note respectively $S_{C D S}$ and $\left.S_{b o n d}\right)$.

We note $\tilde{b}$ is the market price for the CDS, equal to $\tilde{b}=b+S_{C D S}$ and $\tilde{y}$ is the market price for the bond, equal to $\tilde{y}=y+S_{\text {bond }}$. Then, taking into account liquidity, equation (16) is expressed as:

$$
\tilde{b}=\tilde{y}-r-\left(S_{b o n d}-S_{C D S}\right)
$$


To conclude, the parity between CDS and risky bond should hold only for the pure risk component that is priced into the two assets. Then, we can expect a non zero basis when liquidity differences exist.

\subsection{Basis trade with multiple currencies}

The asset management approach that we analyze in this paper leads to change the computation of our liquidity indicator, the basis. Indeed, this latter, as we exposed above, is only true while the investor have dollar denominated assets. However, an asset manager who has a sovereign debt portfolio, invests in several different instruments that are denominated in several different currencies, especially concerning the local sovereign debt market. Thus, the CDS Bond Spread basis that compares CDS premium denominated in dollar and the local currency denominated sovereign debt is biased. To tackle this problem, we compute and correct the P\&L or profit and loss, of an investment strategy corresponding to the basis. In other words, buying/selling both instruments when the basis is negative/positive. The computation of the $\mathrm{P} \& \mathrm{~L}$ is the way that traders refer to the daily change of the value of their trading positions. The $\mathrm{P} \& \mathrm{~L}$ is generally defined as the difference between the value at time $t+1$ and the value at time $t$. In other words, the $\mathrm{P} \& \mathrm{~L}$ of an asset is the profit or the loss that this asset makes between two dates. In this sense, we can split the P\&L between two parts: the Mark-to-Market (MTM hereafter) part and the Carry part. The first one is the gain (or the loss) obtained selling the asset. In other words, this is the difference between the buying price and the selling price of the asset. The second one, called the carry, is the gain (or the loss) that the asset allows to access during the studying period (in our case, one day).

Schematically, we can write the P\&L of an asset as:

$$
P \& L=M T M+C a r r y
$$

Both CDS and Generic bonds P\&L are computed at a daily frequency, and thus, without taking into account of the carry. Indeed, this component is close to be null as, for example, in the case of a bond for which, the coupon is almost equal to zero holding the bond only one day. 


\section{Generic Bond P\&L}

The MTM component of the P\&L of an asset is the same whatever the asset is, i.e the difference between prices at two distinct dates. In the case of a bond, it can be expressed as the variation of the yield-to-maturity (YTM hereafter) multiplied by the sensitivity of a one unit variation. Thus, we note the P\&L of the bond as:

$$
P \& L_{t}^{\text {bond }}=\left[Y T M_{t}-Y T M_{t-1}\right] \times \operatorname{sensi}_{t}^{\text {bond }}
$$

where $s e n s i_{t}^{\text {bond }}$ is defined as the opposite of the Modified Duration, i.e:

$$
\operatorname{sensi}_{t}^{\text {bond }}=\frac{D}{\left(1+Y T M_{\%}\right)}
$$

However, in our case, we have to take into account that the bond is not issued in the same currency than the CDS. We need to correct the P\&L of the generic bond by the FX exchange rate. Note $P B_{t}$ the present value of the bond in local currency and $X_{t}$ the exchange rate at time $t$, thus, we know that the dollar price's variation is expressed as:

$$
\left[P B_{t}-P B_{t-1}\right]_{\$}=\frac{P B_{t+1}}{X_{t+1}}-\frac{P B_{t}}{X_{t}}
$$

Linearizing this expression, we can separate the MTM component of the bond's P\&L in two parts:

$$
\left[P B_{t}-P B_{t-1}\right]_{\$} \simeq \frac{1}{X_{t}}\left(P B_{t+1}-P B_{t}\right)-\frac{P B_{t}}{X_{t}}\left(\frac{X_{t+1}-X_{t}}{X_{t}}\right)
$$

We find on this expression the gain (or loss) due to the variation of the bond's price and the gain (or loss) due to the variation of the exchange rate. Crossing the expression of P\&L that we seen before in equation (18), we obtain:

$$
\left[P B_{t}-P B_{t-1}\right]_{\$} \simeq \frac{1}{X_{t}}\left[\left(Y T M_{t}-Y T M_{t-1}\right) \times \operatorname{sensi}_{t}^{\text {bond }}\right]-\frac{P B_{t}}{X_{t}}\left(\frac{X_{t+1}-X_{t}}{X_{t}}\right) .
$$




\section{CDS P\&L}

As we seen before, the trading horizon is a day. Moreover, we know that the price of a CDS strategy at the issuance is equal to zero. Thus, the MTM component of the P\&L, equal to the difference between the price of buying and selling, is finally equal to the selling price. In the case of CDS, we are able to express the price at time $t$ as the product of premium's variation between $t$ and the issuance date, and the sensitivity to a change of $1 \mathrm{bp}$ of the CDS premium. Summing up, the P\&L of the CDS is expressed as:

$$
\left[P C_{t}-P C_{t-1}\right]=P C_{t}=\left[S_{t}-S_{t-1}\right] \times \operatorname{sensi}_{t}^{C D S},
$$

where $P C_{t-1}$ corresponds to the price at issuance, equal to zero.

Using a continuous time Poisson model, the sensitivity of a 1bp premium variation is equal to:

$$
\text { sensi }_{t}^{C D S}=\int_{0}^{T} e^{-(r+\lambda) \theta} d \theta=\frac{1-e^{-(r+\lambda) T}}{r+\lambda}
$$

where $\lambda=\frac{S_{t}}{1-R R}$ with $R R$ is the recovery rate.

After having computed these time series of P\&L, we can easily calculate the CDS Bond Spread Basis. Indeed, when the basis is negative, we buy both the CDS protection and the bond. Thus, we make the sum of the two P\&L. Obviously, this is the opposite situation in the case of a positive basis.

\subsection{Contagion and RSDC model}

Financial contagion refers to the notion that financial markets move more closely together during turmoil (Bekaert and Harvey (2003)). Rigobon (2001) recall that if economists agree about which events have constituted instances of contagion, there is still no consensus on a definition of contagion. The World Bank provides three definitions of contagion: (i) Broad definition:

(i) debt crises in 1982, (ii) the Mexican Tequila effect in 1994, (iii) the Asian crisis in 1997, (iv) the Russian and LTCM crisis in 1998, (v) Brazilian devaluation in 1999, (vi) the Internet Bubble in 2000, (vii) the Argentina default crisis in 2001 and recently (viii) the subprime crisis. 
contagion is the cross-country transmission of shocks or the general cross-country spillover effects., (ii) Restrictive definition: Contagion is the transmission of shocks to other countries or the cross-country correlation, beyond any fundamental link among the countries and beyond common shocks. This definition is usually referred as excess co-movement, commonly explained by herding behavior, (iii) Very restrictive definition: Contagion occurs when cross-country correlations increase during crisis times relative to correlations during tranquil times. The latter is the more restrictive definition but is also the most widely used to measure it. Contagion occurs when cross-country correlations increase during troubled periods relative to correlations during tranquil times. In the main stream of literature, the analysis of contagion is mostly concentrated on testing the stability of econometric model parameters. However, Forbes and Rigobon (2002) show that the problem of heteroscedasticity has to be taken into account in order to measure pure contagion and not interdependence effects.

\subsection{Contagion models}

To our knowledge, the first empirical study of financial market contagion has been made by King and Wadhwani (1990) who show that an increase in price volatility in the United States leads to a rise in the correlation of returns across markets. However, although financial contagion is a major concern in literature, it is still not clear how to measure it. Indeed, there is no consensus about its definition. The broad one describes contagion as a general process of shock transmission across countries. However, this definition does not allow to measure contagion effects considering data availability. Thus, we find in literature some papers that use the restrictive definition. This latter characterizes the financial contagion as the propagation between countries of shocks in excess of what should be expected by fundamentals and considering the co-movements triggered by the common shocks. However, although more restrictive, this definition implies another measurement problem. Indeed, as Bekaert and Harvey (2003) emphasize, there may have disagreement considering the definition of fundamentals. As a result and following Forbes and Rigobon (2001), the main part of the literature uses the very restrictive definition explaining a contagion phenomena as the change in the transmission mechanisms that take place during a turmoil period.

This third definition has the advantage of easily allowing to measure contagion effects as in 
Bertero and Mayer (1989), King and Wadhwani (1990) or Calvo and Reinhart (1996) that are interested in correlation shifts during turmoil times. Thus, measuring contagion effects resumes to estimating jumps in the correlation between financial time series, or, in other words, if the parameters of the econometric model shift when turmoils occur. In this way, Rigobon (2001) proposes a good survey of parameter stability tests, which are mainly based on Ordinary Least Square estimates, Principal Components, Probit models and correlation coefficient analysis. Rigobon (2000), Forbes and Rigobon (2001), Rigobon (2003a), Rigobon (2003b) propose to study difference in change of the covariance. However, many studies point out a number of methodological problems and particularly the problem of heteroscedasticity. Rigobon (2001) and Forbes and Rigobon (2002) who generalize the approach of Boyer et al. (1999) show that correlation coefficients are biased. These latter are conditional on market volatility. During turmoil periods, market volatility increases and estimates of cross market correlations are biased upward. Indeed, this can lead to accept the contagion hypothesis while false. The authors develop an adjusted correlation coefficient that correct the bias caused by heteroscedasticity. They distinguish pure contagion from interdependence and show that there is no contagion but interdependence during the Mexican or the Asian crisis contrary to previous findings. Indeed, interdependence and pure contagion do not have the same effects on asset allocation strategies. The first is characterized by an increase of the correlations between countries. However, this fact is only due to the rise of volatility for all of concerned countries. Moreover, pure contagion is defined as a rise in correlation that is not the result of economic fundamentals and an increase of volatility. Pure contagion has a biggest impact on the principle of diversification, then it appears crucial to correct the volatility to avoid spurious results.

Thus, many studies, using different econometric methods tried to avoid the problem of heteroscedasticity. Among them, ARCH and GARCH (for Generalized AutoRegressive Conditional Heteroskedasticity) models are largely used in contagion analysis. Hamao et al. (1990) estimate conditional variance with GARCH model and test the correlation between three different markets. Edwards and Susmel (2001) include regime switching in a ARCH modeling to take into account systematic changes. Their model points out large correlations during times of high market volatility, that confirms the existence of contagion effects. However, multivariate GARCH

after bias correction of heteroscedasticity 
models provide more efficient tools for analyzing comovements and volatility spillover between financial assets. Wang and Nguyen Thi (2007), Chiang et al. (2007) or Naoui et al. (2010) also estimate contagion with Dynamic Conditional Correlation that allow for tracking the evolution of the correlation between two or more assets. Kenourgios et al. (2010) use an Asymmetric Generalized Dynamic Conditional Correlation model and study the correlations between the four BRIC countries (i.e: Brazil, Russia, India and China), the US and UK markets. The use of an asymmetric model allows to see that bad news increase dramatically the equity conditional correlations among the BRIC and developed markets.

In addition to the problem of heteroscedasticity, Boyer et al. (1999) point out that the methods previously described have an exogenous definition of the crisis periods that may lead to spurious conclusions. Using a state-space model with a time-varying volatility specification is the solution to tackle this problem. Billio and Caporin (2005) propose a multivariate Markov Switching Dynamic Conditional Correlation GARCH model to estimate contagion effects. This class of models allows for discontinuity in the propagation mechanism to assume that international propagation mechanisms are discontinuous. A markov chain is introduced to describe this discontinuity and allows the endogenous definition of the crisis periods. Moreover, dynamic correlation permits to analyze the dynamics of contagion. Many other authors explore Markov switching models like Ramchand and Susmel (1998), Chesnay and Jondeau (2001) or Ang and Bekaert (2002). Billio et al. (2005) show the Markov switching model abilities to estimate contagion. This approach defines contagion as a break that produces non-linearities in the linkages among financial markets. They emphasize that when using Markov switching models: (i) the heteroscedasticity problem is solved, (ii) the definition of the crisis periods is made endogenously, (iii) the estimations are more efficient because of the full-information approach and (iv) the distinction between long and short run breaks in the factor loadings of the long and short run factors risk is allowed.

Our approach is in the line of Pelletier (2006) that has been used in the context of portfolio allocation [Giamouridis and Vrontos (2007)]. It allows in particular to decrease the number of variance parameters to consider. Thus, our model is a combination of a mixture model for the correlation matrix and a Threshold GARCH model [or TGARCH, Zakoian (1994)] to take into account asymmetric volatility dynamics. However, our estimation method imposes to assume 
that the heteroscedasticity is asset specific and not common across assets.

Note the $K$ asset returns are defined by:

$$
r_{t}=H_{t}^{1 / 2} U_{t},
$$

where $U_{t} \mid \Phi_{t-1} \sim \operatorname{iid}\left(0, I_{K}\right), U_{t}$ is the $T \times K$ innovation vector, and $\Phi_{t}$ is the information available up to time $t$.

The conditional covariance matrix $H_{t}$ is decomposed into [Bollerslev (1990) or Engle (2002)]:

$$
H_{t} \equiv S_{t} \Gamma_{t} S_{t},
$$

where $S_{t}$ is a diagonal matrix composed of the standard deviation $\sigma_{k, t}, k=1, \cdots, K$ and $\Gamma_{t}$ is the $(K \times K)$ correlation matrix. Both matrices are time varying.

The conditional variance follows a $\operatorname{TGARCH}(1,1)$ such that:

$$
\sigma_{i, t}=\omega_{i}+\alpha_{i}^{-} \min \left(\epsilon_{i, t-1}, 0\right)+\alpha_{i}^{+} \max \left(\epsilon_{i, t-1}, 0\right)+\beta_{i} \sigma_{i, t-1},
$$

where $\omega_{i}, \alpha_{i}^{-}, \alpha_{i}^{+}$and $\beta_{i}$ are real numbers.

Under assumptions of: $\omega_{i}>0, \alpha_{i}^{-} \geq 0, \alpha_{i}^{+} \geq 0$ and $\beta_{i} \geq 0, \sigma_{i}, t$ is positive and could be interpreted as the conditional standard deviation of $r_{i, t}$. However, it is not necessary to impose the positivity of the parameters and the conditional standard deviation is the absolute value of $\sigma_{i, t}$. To take into account asymmetries estimating pure contagion effects in order to improve the filtering of co-movements.

The correlation matrix is defined as:

$$
\Gamma_{t}=\sum_{n=1}^{N} \mathbb{1}_{\left(\Delta_{t}=n\right)} \Gamma_{n},
$$

where $\mathbb{1}$ is the indicator function, $\Delta_{t}$ is an unobserved Markov chain process independent from $U_{t}$ which can take $N$ possible values $\left(\Delta_{t}=1 \cdots, N\right)$ and $\Gamma_{n}$ are correlation matrices. 
Regime switches are assumed to be governed by a transition probability matrix $\Pi=\left(\pi_{i, j}\right)$, where

$$
\operatorname{Pr}\left(\Delta_{t}=j \mid \Delta_{t-1}=i\right)=\pi_{i, j}, i, j=1, \cdots, N .
$$

This approach allows to discriminate between on the one hand the volatility dynamics through $S_{t}$ and on the other one the correlation dynamics through the state variable $\Delta_{t}$.

Finally, coming back to liquidity, we know that the contagion between markets drives their in and outflows, and liquidity moves consequently. In the line of the above approach, we can link contagion and liquidity moves by comparing the commonalities between the liquidity indicators introduced in the previous sections and the volatility and correlation series. If the commonality is between liquidity and volatility, there is no contagion effect. On the contrary, if the liquidity shock has an impact on the correlation matrix, liquidity can be considered as a contagion channel.

\section{$5 \quad$ First Results}

EM are associated with very interesting investment opportunities for any investor seeking both returns enhancement and diversification. Moreover, the choice of this example is motivated by the historical concentration of contagion effects related to emerging economies. Moreover, EM investments must be carefully analyzed. They suffer from additional risk, such as liquidity risk and, in some cases, systemic risk, that are not taken into account in the basic mean-variance approach. In this section, we describe data and we show the behavior of our liquidity indicator over time.

\subsection{Data description}

In this paper, we use data on sovereign bond yield spreads, sovereign CDS, interest rates and foreign exchange rates. We have 18 emerging markets: Argentina, Brazil, Chile, China, Czech, Egypt, Hungary, India, Indonesia, Mexico, Peru, Philippines, Poland, Russia, Slovakia, South Africa, Taiwan, Thailand, Turkey. However, for data availability reasons, we restrict our analysis 
to 9 of them that are present in sovereign debt from 01/01/2007 to $25 / 02 / 2011$.

All data are downloaded for emerging market countries of Lehman Brothers MSCI Emerging Market Index before filtering. The time series covers many of the recent crisis and allows us to explore emerging markets behavior during economic disturbances. We obtain sovereign CDS premium daily data from Bloomberg and all other data from Thomson DataStream. These CDS Premiums are based on 5-year U.S. dollar contracts, for senior claims, and they assume a recovery rate of $25 \%$. We use as risk-free rate the US Swap rate $30 / 360$ paid semi annually. Table 5 gives the data availability for each of the sovereign borrowers. We take the smallest common time period across countries.

\begin{tabular}{rcccccc} 
& Mean & Std & Minimum & Median & Maximum & Relative Std \\
\hline \hline Brazil & 151.45 & 86.17 & 61.50 & 121.84 & 586.41 & $56.90 \%$ \\
Chile & 84.36 & 64.77 & 12.50 & 72.53 & 322.96 & $76.78 \%$ \\
Hungary & 217.13 & 150.55 & 17.34 & 215.00 & 629.76 & $69.34 \%$ \\
Mexico & 143.40 & 100.28 & 28.17 & 118.63 & 601.21 & $69.93 \%$ \\
Poland & 109.52 & 84.65 & 7.67 & 117.00 & 415.00 & $77.30 \%$ \\
Russia & 214.34 & 201.95 & 36.88 & 146.75 & 1113.38 & $94.22 \%$ \\
South Africa & 165.50 & 114.50 & 24.57 & 145.28 & 654.96 & $69.18 \%$ \\
Thailand & 114.41 & 69.42 & 31.84 & 103.23 & 489.56 & $60.67 \%$ \\
Turkey & 231.86 & 101.96 & 118.61 & 193.06 & 824.61 & $43.97 \%$ \\
\hline
\end{tabular}

Table 1 - Summary statistics for CDS premiums from 1-1-2007 to 2-25-2011. Results are expressed in basis points and percentage.

Table (1) provides descriptive statistics for the sovereign CDS premiums, in other words, for the sovereign default risk. The wide range of averages highlights the high degree of heterogeneity among countries with a maximum average of 231.86 for Turkey and a minimum of 84.36 for Chile. Moreover, the relative standard deviation ranges from $44 \%$ for Turkey to $94 \%$ for Russia. For example, the cost of credit protection for Russia ranges from 36.88 to 1,113.38 basis points when it ranges for Chile only from 12.50 to 322.96 .

\subsection{Liquidity Description}

Even knowing that the basis is theoretical not only driven by the market liquidity, this is important to summarize the empirical commonality studying its correlation with a well known liquidity indicator, the Bid-Ask spread. On the one hand, we start this study by analyzing

Brazil, Chile, Hungary, Mexico, Poland, Russia, South Africa, Thailand and Turkey. 
the Pearson's correlation coefficient. The first line of the table 2 analyzes the link between our sovereign debt market liquidity indicator and Bid-Ask spread of the sovereign CDS market. The correlations are all greater than 0.53 in absolute value that confirms the good behavior of the basis as a liquidity indicator or rather than an illiquidity indicator as we highlight the negative correlation with the Bid-Ask spread. We focus on the commonalities between countries and this is studied in this paper comparing the timing of re-correlation phenomena in our multivariate analysis.

\begin{tabular}{cccccccccc} 
& Brazil & Chile & Hungary & Mexico & Poland & Russia & South Africa & Thailand & Turkey \\
\hline \hline Basis/Bid-Ask Spread & $-0,58$ & 0,67 & $\mathbf{- 0 , 1 8}$ & $-0,62$ & $\mathbf{- 0 , 1 8}$ & $-0,94$ & $-0,58$ & $-0,53$ & $-0,91$ \\
\hline
\end{tabular}

Table 2 - Correlations between Bid Ask Spread and Basis. The coefficients displayed here are computed by Pearson methodology. Low correlations (less than 0.5 ) are in bold type.

Our empirical study of the market liquidity indicators confirms some stylized facts and the collapse of Lehman Brothers just as the 2007-2008 financial crisis are strongly highlighted. The figure 2 presents, for each of the 9 emerging countries, the CDS Bond Spread basis expressed in P\&L. The first conclusion is that an arbitrage strategy started in 2007 could be profitable. Indeed, we show that all basis became clearly negative between 2007 and 2011. Every basis except Russia have positive values of P\&L at the begin of 2007. Moreover, all basis time series have practically the same behavior. They were stable from the start of 2007 until the middle of 2007, when they started to decrease. Note that the basis highlights problems of liquidity from the summer 2007, i.e the start of the financial crisis while many indicators just show the Lehman Brothers collapse.

After a first decrease in the middle of 2007, the basis fall down at the end of 2008. Moreover, the indicators became extremely volatile until 2009. Except Hungary for which the basis stays highly volatile between 2009 and 2001, all other countries see their basis come back to a stable state. However, the liquidity level, although stable, are lower that before the summer 2007. Furthermore, we show that the levels of liquidity are between 0.1848 for Brazil and $-2,3384$ for Hungary. The level of basis is however homogeneous among our sample. This first graphical analysis allows us to see the high correlations that it could have between liquidity indicators. However, we have to study the commonalities with a non linear multivariate model that tackles the heteroscedasticity problem to estimate pure contagion effects after controlling the volatility. 

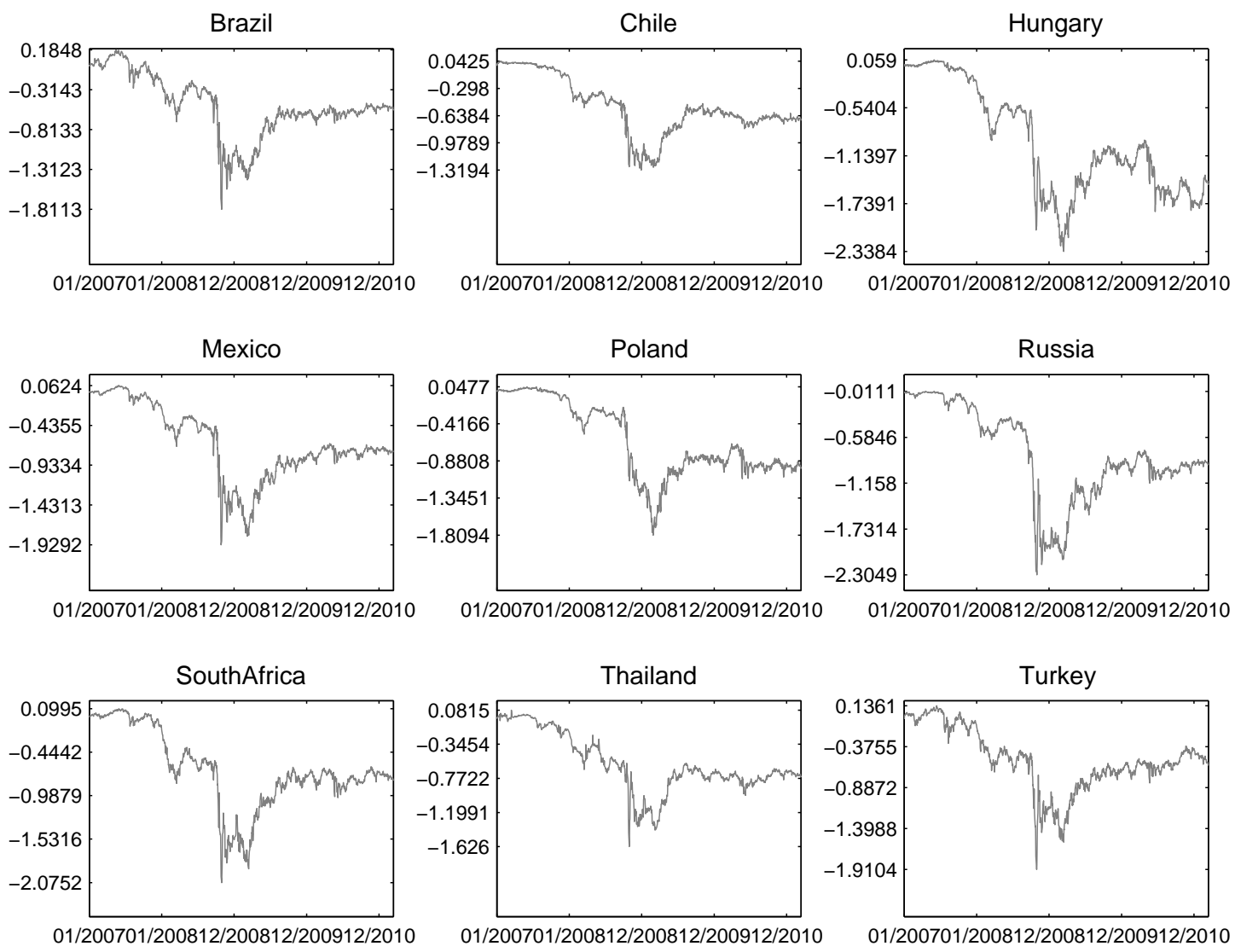

Figure 2 - Basis for each of the 9 emerging countries. The results are presented on the whole sample from the $01 / 01 / 2007$ to the $02 / 25 / 2011$.

\section{Pure contagion rather than interdependence}

Keeping in mind that the main fear of an asset manager is to get stuck with unwanted position, we present some results that show a re-correlation phenomena during the last crisis. This concern is especially true when the re-correlation effects come from a liquidity problem. Thus, we focus on the smoothed probabilities to be in the state of high correlations and the difference between the correlations of being in one or an other state. We analyze the sovereign debt market and we show that the behavior of the liquidity indicator is similar for most countries of our sample. Moreover, we highlight that pure contagion effects occurs on the sovereign debt market.

The major part of the contagion measurement literature is devoted to test the parameter stability of an econometric model. Indeed, a shift of these parameters is interpreted as a change in terms of correlation, i.e. a contagion phenomena. However, following Pelletier (2006), we study the probability to be in a state of "low correlations" versus "high correlations". Our first results 
show that the first one is assimilated to "normal" times while the second one is assimilated to "crisis" times. Thus, we start our study by analyzing the re-correlation phenomena in terms of prices before to focus on liquidity problems. Our aim is to reveal the existence of contagion effects in emerging markets during the last crisis, particularly in terms of financial flows. Although both of these two subjects are actively debated on the recent literature, there are only few papers that study both contagion effects and liquidity, especially together. Moreover, we study emerging countries because since the recent crisis, we saw that the risk is no longer supported by the banks but by the states. Thus, sovereign CDS market has also a key role to play in the detection of crisis. It could be considered as a leading indicator of emerging economy turmoils.

We first present results for price data on the sovereign debt market. We focus on 9 emerging countries that is already too many to make the estimation of our model with a one-step likelihood maximization method. Thus, we firstly estimate univariate TGARCH for each of countries in our dataset. We report the results of the estimation of TGARCH for CDS data in table 3. We only present the detailed results for the model with TGARCH since the results for the correlation models do not depend on the univariate model for the standard deviations used in the first step. The correlation model are robust to the specification of the standard deviations. Thus, we choose TGARCH model to take into account the asymmetry in the variance. We not only consider a shift in terms of correlations with the Markov switching focusing on the correlation matrix but we control the correlation analysis from asymmetric variance problems. The results of TGARCH estimation present a brief statement of the market price behavior. We see for the CDS market that a decrease of the CDS premium have a smaller impact on the return volatility than an increase. Indeed, the CDS premium is a hedge against the country risk of default. Thus, an increase of their value means that the risk of default of the country increases, that is a bad news as a negative returns for an equity.

Looking at Figure 3 where we plot the smoothed probabilities of being in regime two at each point of time for CDS market and Basis. We see that the correlations appear to be dynamic. This figure shows that we frequently move between regimes. For each date, there is little uncertainty about the regime of correlations. In our case, the regime two corresponds to the high correlation state. The process is spending more time in regime one on our range of data and spells in regime one are shorter on average than in regime two. This is explained by the estimate of the 


\begin{tabular}{cccccccccc} 
& Brazil & Chile & Hungary & Mexico & Poland & Russia & South Africa & Thailand & Turkey \\
\hline \hline \multirow{2}{*}{ omega } & $8.56 \mathrm{E}-06$ & $1.40 \mathrm{E}-06$ & $5.21 \mathrm{E}-07$ & $1.06 \mathrm{E}-06$ & $6.26 \mathrm{E}-07$ & $1.31 \mathrm{E}-06$ & $1.04 \mathrm{E}-06$ & $1.52 \mathrm{E}-06$ & $1.67 \mathrm{E}-05$ \\
& 4.26E-06 & $2.69 E-06$ & $3.51 \mathrm{E}-07$ & $1.01 \mathrm{E}-06$ & $3.53 E-07$ & $1.41 \mathrm{E}-06$ & $9.03 E-07$ & $1.89 E-06$ & $1.00 \mathrm{E}-05$ \\
alpha- & 0.0244 & 0.0640 & 0.0907 & 0.0000 & 0.0687 & 0.0565 & 0.0518 & 0.0819 & 0.0209 \\
& 0.0152 & 0.0303 & 0.0548 & 0.0149 & 0.0303 & 0.0234 & 0.0326 & 0.0311 & 0.0365 \\
alpha+ & 0.1993 & 0.2111 & 0.0549 & 0.2007 & 0.1513 & 0.1201 & 0.0991 & 0.0956 & 0.1582 \\
& 0.0678 & 0.0975 & 0.0317 & 0.0464 & 0.0380 & 0.0310 & 0.0256 & 0.0364 & 0.0529 \\
beta & 0.8757 & 0.8303 & 0.8816 & 0.8994 & 0.8554 & 0.8833 & 0.8984 & 0.8701 & 0.8874 \\
& 0.0214 & 0.0642 & 0.0479 & 0.0209 & 0.0340 & 0.0265 & 0.0346 & 0.0367 & 0.0502 \\
\hline
\end{tabular}

Table 3 - TGARCH Parameters for CDS data. Standard deviations are in italic.

transition probability matrix, which is very similar across the various models with two regimes. The probability of being in regime two at time $t$ conditional on being in regime two at time $t$, $p_{2,2}$ is around 0.99 . That means a very high level of persistence in the Markov chain. Indeed, we are almost in the case of an absorbing state. In comparison, for regime one this probability is around 0.9. Despite the fact that these probabilities are close in value, as Pelletier (2006) shows, there exists a large difference between these values. Indeed, after 5 periods, these probabilities are respectively almost equals to 0.95 and 0.55 . We show that the magnitudes of almost all the correlations in regime one are smaller than in regime two. Indeed, the correlations is greater for each pair of countries except for Mexico-Russia and Mexico-Turkey on the CDS market. Moreover, the log-likelihood of the RSDC estimation is greater than those of CCC estimation by more than 200 points.

These results allow us to split the whole sample into two periods. Before the end of 2008, the probability to be in regime two (i.e. high correlations) stays at a low level and relatively less volatile. We can see some peaks but as the probability $p_{1,1}$ is equal to 0.89 we observe from time to time, some peaks during the "calm period". However, after the collapse of Lehman Brothers, we see that this probability is very high, and almost always equal to one. This fact is confirmed by the behavior, almost absorbing, of the state two. Indeed, the probability to be in state two both at time $t$ and $t-1\left(p_{2,2}\right)$ is equal to 0.99 . Then, we show that, on the sovereign debt market, the behavior of the risk supported by the countries is more correlated during the last crisis than during the period before. Whether we consider the definition of the contagion given by Forbes and Rigobon (2001), and the distinction made between interdependence and pure contagion, the recent crisis exhibits strong pure contagion effects.

Indeed, $0.99^{5}=0.95$ and $0.90^{5}=0.55$ 


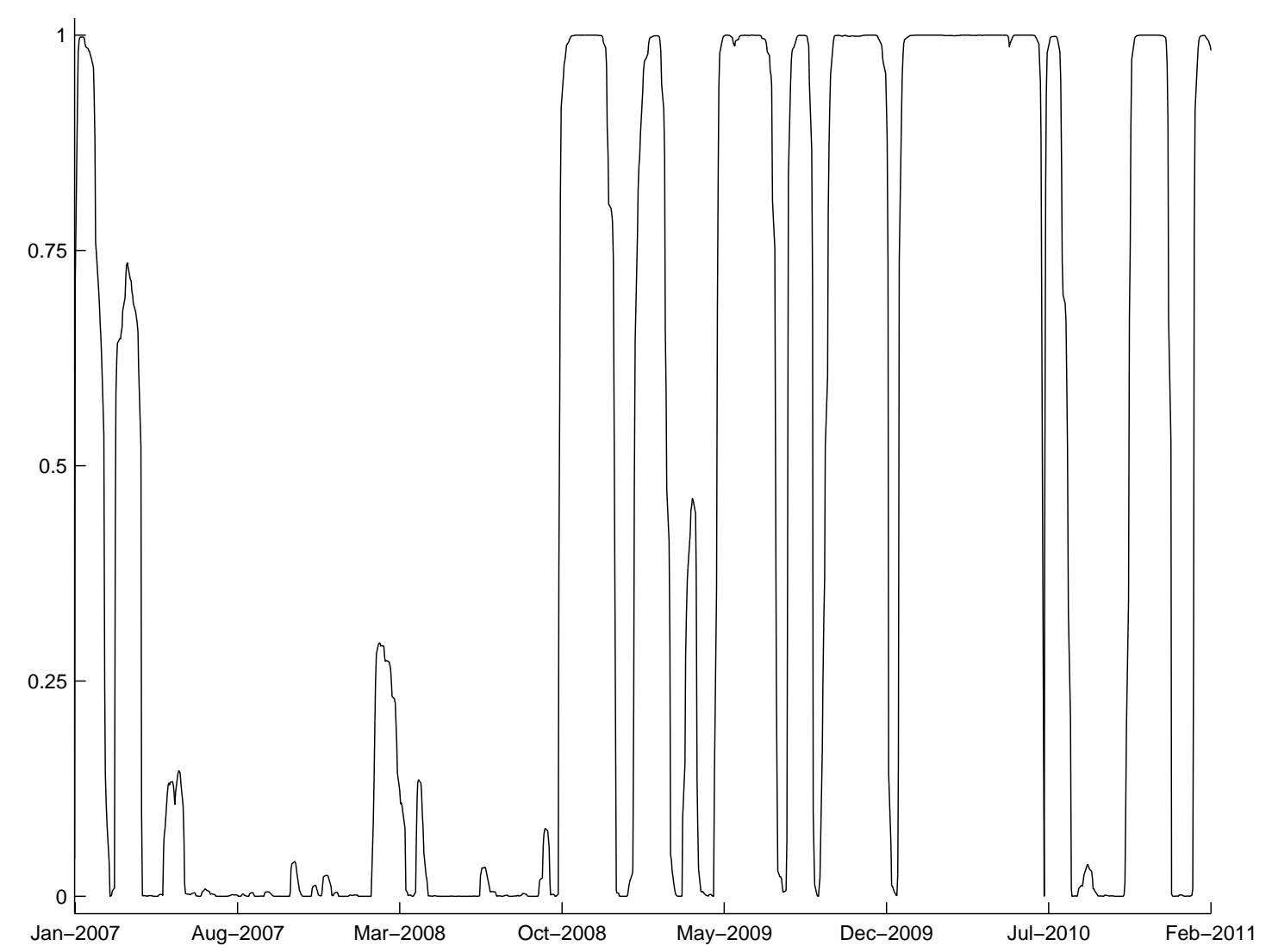

Figure 3 - Smoothed Probabilities to be in the state of high correlations. Smoothed probabilities are computed following Hamilton, chapter 22. The results are both for the CDS market between 01/01/2007 and 25/02/2011.

To confirm our results, we have to define if the two correlation matrices are significantly separate. In other terms, we test the number of regimes. However, the Markov switching approach in our model does not allow to apply standard methods. Indeed, under the null hypothesis, a nuisance parameter is not identified. Garcia (1998) shows that asymptotic theory works for Markov switching only assuming the validity of the score distribution. However, the asymptotic distribution is not so far from the standard Chi-square distribution while our likelihood ratio statistic is much greater than critical value of this distribution. Then, we conclude that a model is better with two regimes and confirm the significance of the difference between the two correlation matrices. To compute this statistic, we have to compare the likelihood of our model, RSDC with two regimes and the CCC model which is assimilated to a RSDC with only one regime.

Whether contagion effects on prices are strong as we see below, another key point in the crisis impact is the liquidity. We focus on the liquidity contagion effects of sovereign debt market. 


\begin{tabular}{rccccccccc} 
& Brazil & Chile & Hungary & Mexico & Poland & Russia & South Africa & Thailand & Turkey \\
\hline \hline Brazil & & 0.363 & 0.303 & 0.146 & 0.366 & 0.048 & 0.172 & 0.295 & 0.045 \\
Chile & 0.240 & & 0.181 & 0.279 & 0.253 & 0.314 & 0.193 & 0.181 & 0.224 \\
Hungary & 0.218 & 0.177 & & 0.276 & 0.232 & 0.316 & 0.205 & 0.281 & 0.342 \\
Mexico & 0.090 & 0.177 & 0.202 & & 0.353 & 0.018 & 0.158 & 0.242 & 0.091 \\
Poland & 0.298 & 0.189 & 0.281 & 0.287 & & 0.381 & 0.355 & 0.277 & 0.438 \\
Russia & 0.016 & 0.199 & 0.329 & $\mathbf{- 0 . 0 1 1}$ & 0.386 & & 0.114 & 0.230 & 0.069 \\
South Africa & 0.154 & 0.180 & 0.245 & 0.117 & 0.396 & 0.159 & & 0.245 & 0.249 \\
Thailand & 0.097 & 0.055 & 0.144 & 0.050 & 0.139 & 0.113 & 0.173 & & 0.270 \\
Turkey & 0.001 & 0.171 & 0.287 & $-\mathbf{0 . 0 1 0}$ & 0.413 & 0.041 & 0.178 & 0.120 & \\
\hline
\end{tabular}

Table 4 -Differences between the two regimes correlations matrices (high minus low). The blue part of the matrix corresponds to the CDS market and the black part corresponds to the Basis.

Indeed, it is crucial for an asset manager to know if the re-correlation problem that we show above is due to a liquidity problem. If this case occurs, the asset manager could get stuck with an unwanted sovereign debt. Thus, we apply the same model as below on our liquidity indicator: the CDS-bond basis.

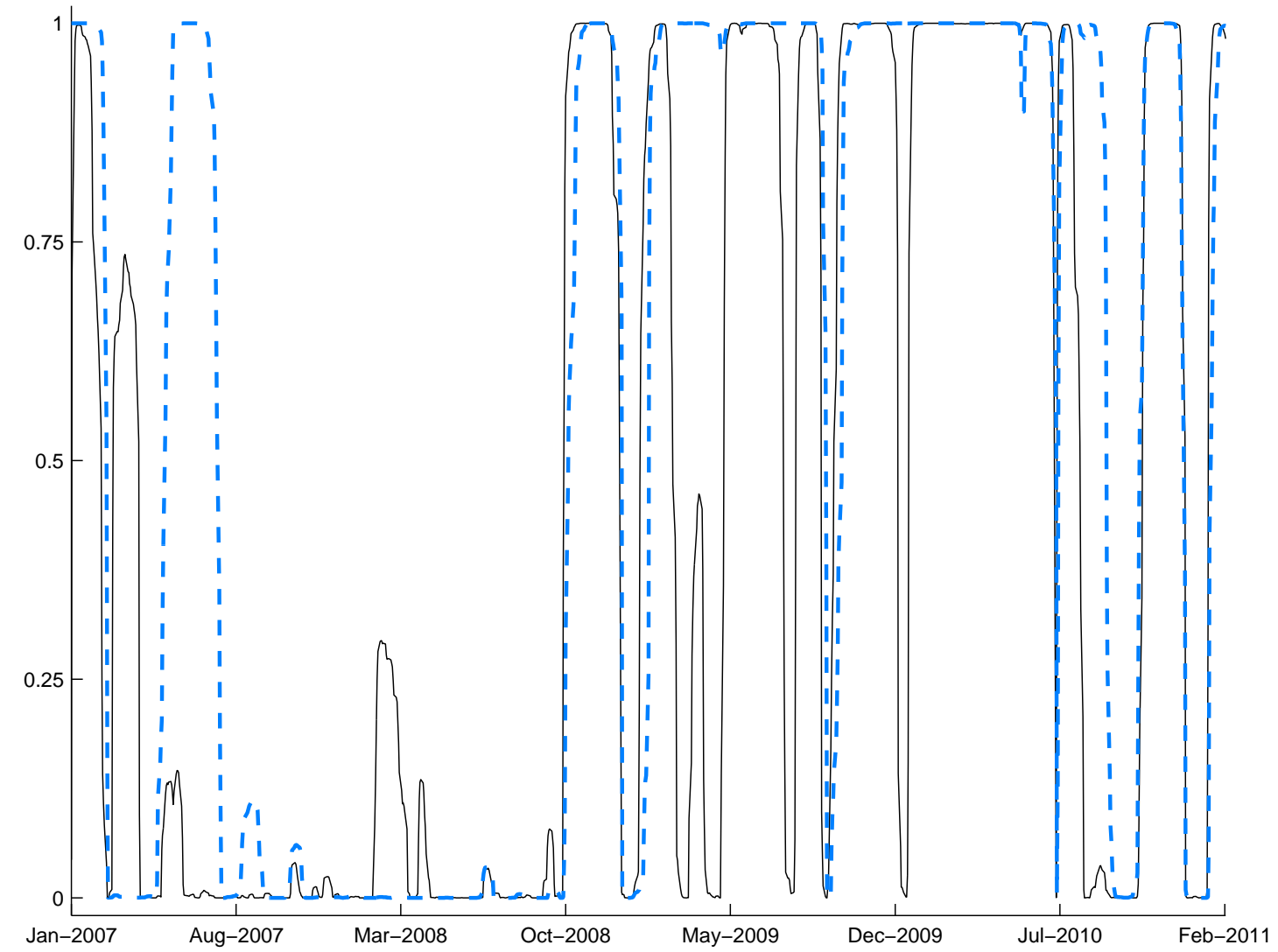

Figure 4 - Smoothed Probabilities to be in the state of high correlations. CDS market is represented by dark line and Basis by the blue dotted line. Smoothed probabilities are computed following Hamilton, chapter 22 . The results are both for the CDS market and the basis between 01/01/2007 and 25/02/2011. 
As we see on the figure 4, the probabilities to be in the state two of the CDS market and the basis are highly correlated. Especially for the regime switching in October 2008 which occurs exactly at the same time on both of two. This result means that the re-correlation phenomenon on the CDS market is due to a liquidity problem on the sovereign debt market. The regimes of CDS premiums are similar to those of the CDS Bond Spread Basis. In other words, when CDS are high and investors are funding constrained, the basis deviates from parity.

\section{Conclusion}

EM have experienced many financial crisis with contagion problems. However, they are today the key drivers for global growth of the world economy. They propose very attractive investment opportunities for asset managers who consider them as an asset class. Nevertheless, the main risk for an asset manager is to lose diversification benefits in his/her portfolio. In this paper, we analyze a new data set of emerging markets, only recently studied. We propose a liquidity measure for a long term analysis under constraint of data using the deviations from the Covered Interest Parity and the CDS bond spread basis as liquidity indicators respectively for FX and sovereign debt markets. We implement a statistical model to detect and analyze contagion capable to differentiate pure contagion and interdependence. Indeed, the re-correlation phenomena empirically showed prohibits to use Markowitz approach. This analyze needs a non-linear model to capture heteroscedasticity and shifts in correlations. Our approach is in the line with Pelletier (2006). However, we use a Threshold GARCH model to tackle the heteroscedasticity problem and focus on pure contagion effects. Then, the possible shifts of correlations are estimated by a regime switching model in the second step of our estimation procedure. Thus, we show that the basis measures emerging market liquidity and there exists a re-correlation effects after October 2008. The difference between correlations during quiet period and turmoil period is significant proving that pure contagion effects occur during the 2007-2008 crisis. This study is particularly relevant because re-correlation phenomena and pure contagion hamper the diversification benefits of an asset allocation and it is crucial for an international portfolio manager to take into account both of these effects. 


\section{References}

Aitken, M. and Winn, R. (1997). What is this thing called liquidity. Securities Industry Research Center of Asia Pacific Sydney, Australia.

Ammer, J. and Cai, F. (2007). Sovereign CDS and bond pricing dynamics in emerging markets: does the cheapest-to-deliver option matter? International Finance Discussion Papers.

Ang, A. and Bekaert, G. (2002). International asset allocation with regime shifts. Review of Financial Studies, 15(4):1137.

Bai, J. and Collin-Dufresne, P. (2011). The determinants of the cds-bond basis during the financial crisis of 2007-2009. SSRN eLibrary.

Bekaert, G. and Harvey, C. (2003). Emerging markets finance. Journal of Empirical Finance, 10(1-2):3-56.

Bertero, E. and Mayer, C. (1989). Structure and performance: global interdependence of stock markets around the crash of October 1987. CEPR Discussion Papers.

Billio, M. and Caporin, M. (2005). Multivariate Markov switching dynamic conditional correlation GARCH representations for contagion analysis. Statistical methods and applications, $14(2): 145-161$.

Billio, M., Duca, M., and Pelizzon, L. (2005). Contagion Detection with Switching Regime Models: a Short and Long Run Analysis. GRETA, Venice.

Bollerslev, T. (1990). Modelling the coherence in short-run nominal exchange rates: a multivariate generalized arch model. The Review of Economics and Statistics, pages 498-505.

Boyer, B., Gibson, M., and Loretan, M. (1999). Pitfalls in tests for changes in correlations. In Federal Reserve Boars, IFS Discussion Paper No. 597R. Citeseer.

Brunnermeier, M. K. and Pedersen, L. H. (2009). Market liquidity and funding liquidity. Review of Financial Studies, 22(6):2201-2238.

Calvo, S. and Reinhart, C. (1996). Capital flows to Latin America: Is there evidence of contagion effects? Policy Research Working Paper Series.

Chesnay, F. and Jondeau, E. (2001). Does correlation between stock returns really increase during turbulent periods? Economic Notes, 30(1):53-80.

Chiang, T., Jeon, B., and Li, H. (2007). Dynamic correlation analysis of financial contagion: Evidence from Asian markets. Journal of International Money and Finance, 26(7):1206-1228.

Choudhry, M. (2006). The credit default swap basis. Bloomberg Pr. 
Dempster, A., Laird, N., and Rubin, D. (1977). Maximum likelihood from incomplete data via the em algorithm. Journal of the Royal Statistical Society. Series B (Methodological), pages $1-38$.

Duffie, D. (1999). Credit swap valuation. Financial Analysts Journal, 55(1):73-87.

Edwards, S. and Susmel, R. (2001). Volatility dependence and contagion in emerging equity markets. Journal of Development Economics, 66(2):505-532.

Engle, R. (2002). Dynamic conditional correlation. Journal of Business and Economic Statistics, 20(3):339-350.

Fontana, A. and Scheicher, M. (2010). An analysis of euro area sovereign cds and their relation with government bonds. SSRN eLibrary.

Forbes, K. and Rigobon, R. (2001). Measuring contagion: Conceptual and empirical issues. International financial contagion, pages 43-66.

Forbes, K. J. and Rigobon, R. (2002). No contagion, only interdependence: Measuring stock market comovements. Journal of Finance, 57(5):2223-2261.

Garcia, R. (1998). Asymptotic null distribution of the likelihood ratio test in markov switching models. International Economic Review, pages 763-788.

Garleanu, N. and Pedersen, L. (2009). Margin-based asset pricing and deviations from the law of one price. Working Paper, UC Berkeley.

Giamouridis, D. and Vrontos, I. (2007). Hedge fund portfolio construction: A comparison of static and dynamic approaches. Journal of Banking \& Finance, 31(1):199-217.

Goyenko, R., Holden, C., and Trzcinka, C. (2009). Do liquidity measures measure liquidity? Journal of Financial Economics, 92(2):153-181.

Gromb, D. and Vayanos, D. (2002). Equilibrium and welfare in markets with financially constrained arbitrageurs. Journal of Financial Economics, 66(2):361-407.

Hamao, Y., Masulis, R., and Ng, V. (1990). Correlations in price changes and volatility across international stock markets. Review of Financial Studies, 3(2):281.

Hasbrouck, J. (2004). Liquidity in the futures pits: Inferring market dynamics from incomplete data. Journal of Financial and Quantitative Analysis, 39(2).

Holmes, R. (1991). On random correlation matrices. SIAM journal on matrix analysis and applications, 12:239.

Hull, J. and White, A. (2000). Valuing credit default swaps I: No counterparty default risk. Journal of Derivatives, 8(1):29-40. 
Kenourgios, D., Samitas, A., and Paltalidis, N. (2010). Financial crises and stock market contagion in a multivariate time-varying asymmetric framework. Journal of International Financial Markets, Institutions and Money.

King, M. and Wadhwani, S. (1990). Transmission of volatility between stock markets. Review of Financial Studies, 3(1):5.

Lesmond, D., Ogden, J., and Trzcinka, C. (1999). A new estimate of transaction costs. Review of Financial Studies, 12(5):1113.

Levy, A. (2009). The cds bond basis spread in emerging markets: Liquidity and counterparty risk effects. Working paper.

Mengle, D. (2007). Credit derivatives: An overview. Economic Review, (Q4):1-24.

Menkveld, A. and Wang, T. (2011). Liquileaks.

Morris, S. and Shin, H. (2004). Coordination risk and the price of debt. European Economic Review, 48(1):133-153.

Naoui, K., Liouane, N., and Brahim, S. (2010). A Dynamic Conditional Correlation Analysis of Financial Contagion: The Case of the Subprime Credit Crisis. International Journal of Economics and Finance, 2(3):85-96.

Pelletier, D. (2006). Regime switching for dynamic correlations. Journal of Econometrics, 131(1-2):445-473.

Ramchand, L. and Susmel, R. (1998). Volatility and cross correlation across major stock markets. Journal of Empirical Finance, 5(4):397-416.

Rigobon, R. (2000). A simple test for stability of linear models under heteroskedasticity, omitted variable, and endogenous variable problems. manuscript, MIT.

Rigobon, R. (2001). Contagion: How to Measure It? NBER Working Papers.

Rigobon, R. (2003a). Identification through heteroskedasticity. Review of Economics and Statistics, 85(4):777-792.

Rigobon, R. (2003b). On the measurement of the international propagation of shocks: is the transmission stable? Journal of International Economics, 61(2):261-283.

Roll, R. (1984). A simple implicit measure of the effective bid-ask spread in an efficient market. Journal of Finance, 39(4):1127-1139.

Wang, K. and Nguyen Thi, T. (2007). Testing for contagion under asymmetric dynamics: Evidence from the stock markets between US and Taiwan. Physica A: Statistical Mechanics and its Applications, 376:422-432. 
Zakoian, J. (1994). Threshold heteroskedastic models. Journal of Economic Dynamics and control, 18(5):931-955.

\section{A Estimation of RSDC}

The estimation of this model is made using a two-step procedure: (i) the univariate estimation of standardized residuals with TGARCH model and maximum likelihood and, (ii) the estimation of correlation matrices and probabilities to be in state $\mathrm{n}(n=1, \cdots, N)$ with an EM algorithm (Dempster et al. (1977)). Using this method is preferable when the number of observed series is more than a few. Indeed, the number of parameters could become very large and the one-step likelihood maximisation becomes untractable.

We should introduce $\theta$ the complete parameter space, that we split in two parts with: $\theta_{1}$ that corresponds to the parameter space of the univariate volatility model and $\theta_{2}$ that corresponds to the parameter space of the correlation model. Firstly, we compute the log-likelihood taking a correlation matrix equal to the identity matrix. In other words, we estimate univariate TGARCH model for each asset.

\section{A.1 First Step}

To model the full covariance matrix, we estimate the standard deviations and the correlations separately. This first step focus on the estimation of standard deviations.

The parameters of univariate TGARCH model are estimated with maximum likelihood, taking the case of a $\operatorname{TGARCH}(1,1)$, as presented in section 1 . We have to specify the distribution of $U_{t}$ in order to estimate the likelihood function that we want to maximize. In our case, $U_{t}$ are iid and normally distributed $\left[U_{t} \sim \mathcal{N}(0,1)\right]$ allowing to consider gaussian likelihood. However, we don't make the assumption that is the true law of $U_{t}$.

Note $\theta_{1}=\left(\omega, \alpha^{-}, \alpha^{+}, \beta\right)$. Thus, the gaussian likelihood is:

$$
L\left(\theta_{1}\right)=L\left(\theta_{1} ; r_{0}, \cdots, r_{T}\right)=\prod_{t=1}^{T} \frac{1}{\sqrt{2 \pi \tilde{\sigma}_{t}^{2}}} \exp \left(-\frac{r_{t}^{2}}{2 \tilde{\sigma}_{t}^{2}}\right)
$$


with $\tilde{\sigma}_{t}$ are obtained recursively $(\forall t \geq 1)$ as:

$$
\tilde{\sigma}_{i, t}=\omega_{i}+\alpha_{i}^{-} \min \left(\epsilon_{i, t-1}, 0\right)+\alpha_{i}^{+} \max \left(\epsilon_{i, t-1}, 0\right)+\beta_{i} \tilde{\sigma}_{i, t-1}
$$

Taking the logarithm and simplifying the expression, we have to minimize the log-likelihood $\tilde{l}_{t}\left(\theta_{1}\right)$ that is defined by:

$$
\tilde{l}_{t}=\tilde{l}_{t}\left(\theta_{1}\right)=\frac{r_{t}^{2}}{\tilde{\sigma}_{t}^{2}}+\log \left(\tilde{\sigma}_{t}^{2}\right)
$$

Thus, $\hat{\theta_{1}}$ is the solution of:

$$
\hat{\theta_{1}}=\underset{\theta_{1}}{\arg \min } \frac{1}{T} \sum_{t=1}^{T} \tilde{l}_{t}\left(\theta_{1}\right)
$$

After the estimation of parameters, we get the standardized residuals, noted $\tilde{U}_{t}$ as:

$$
\tilde{U}_{i, t}=\frac{r_{i, t}}{\tilde{\sigma}_{i, t}}
$$

In the next step, we use it to estimate the correlation matrices. We introduce a regime switching to add dynamic in correlations. It measures the probability to be in the state $n$ (in our case $n=0,1$ corresponding respectively to liquid and illiquid states).

\section{A.2 Second Step}

In this second part of estimation of our model, we use the Expectation Maximization algorithm (EM thereafter). The main advantage is is the possibility to taking into account high number of parameters coming from each $\Gamma_{n}$.

\section{A.2.1 EM Algorithm}

This algorithm is presented in Hamilton (1994, chapter 22). We have to estimate the vector of parameters $\theta_{2}$ :

$$
\tilde{\theta}_{2}=\underset{\theta_{2}}{\arg \min }\left[\frac{1}{2} \sum_{t=1}^{T} K \log (2 \pi)+\log \left(\left|\Gamma_{t}\right|\right)+\tilde{U}_{t}^{\prime} \Gamma_{T}^{-1} \tilde{U}_{t}\right]
$$


Unlike the first step, we have to use Hamilton filter because in this part of the estimation, $\Delta_{t}$ is unobserved. Moreover, the number of parameters increases at a quadratic rate with the number of asset returns. Thus, to realize these estimation, we use EM algorithm that has no restrictions on the number of parameters.

Then, Hamilton (1994, chapter 22) expose that Maximum Likelihood estimates of the transition probabilities (i) and the correlation matrices (ii) satisfy:

$$
\begin{aligned}
& \text { (i) } \quad \tilde{\pi}_{i, j}=\frac{\sum_{t=2}^{T} P\left[\Delta_{t}=j, \Delta_{t-1}=i \mid \underline{\tilde{U}_{T}} ; \tilde{\theta}_{2}\right]}{\sum_{t=2}^{T} P\left[\Delta_{t-1}=i \mid \underline{\tilde{U}_{T}} ; \tilde{\theta}_{2}\right]} \\
& \text { (ii) } \quad \tilde{\Gamma}_{n}=\frac{\sum_{t=1}^{T}\left(\tilde{U}_{t} \tilde{U}_{t}^{\prime}\right) P\left[\Delta_{t}=n \mid \underline{\tilde{U}_{T}} ; \tilde{\theta}_{2}\right]}{\sum_{t=1}^{T} P\left[\Delta_{t-1}=n \mid \underline{\tilde{U}_{T}} ; \tilde{\theta}_{2}\right]} \text { for } n=1,2
\end{aligned}
$$

Estimates of transition probabilities are based on the smoothed probabilities. We could see that $\tilde{\Gamma}_{n}$ is not directly a correlation matrix. It must be rescaled because their diagonal elements are not constrained to be equal to one. Off-diagonal elements are between -1 and 1 . This step is needed because the product of standardized residuals is not constrained to have elements between -1 and 1 . Then we rescale $\Gamma_{t}$ at each iteration as:

$$
\Gamma_{t}=D_{t}^{-1} \tilde{\Gamma}_{t} D_{t}^{-1}
$$

where $D_{t}$ is a diagonal matrix with $\sqrt{\tilde{\Gamma}_{n, n, t}}$ on row $n$ and column $n$.

The algorithm starts with initial values $\tilde{\theta}_{2}^{(0)}$ for the vector $\theta_{2}$. With $\tilde{\theta}_{2}^{(0)}$ we can compute a new vector $\tilde{\theta}_{2}^{(1)}$ based on equations (32) and (33). The algorithm works until the difference between $\tilde{\theta}_{2}^{(m)}$ and $\tilde{\theta}_{2}^{(m+1)}$ is less than a defined threshold.

\section{A.2.2 Computation}

We develop in this subsection the method to compute the EM algorithm. The elements of the transition probabilities matrix, $\tilde{\pi}_{i, j}$ are defined as the ratio of consecutive probabilities $\left(P\left[\Delta_{t}=j, \Delta_{t-1}=i \mid \tilde{U}_{t}, \theta_{2}\right]\right)$ and the probabilities to be in state $j$ at time $t$. They are obtained 
iteratively from $t=1$ to $T$.

Note that, conditional probability is defined by [see Hamilton, (22.3.7)]:

$$
P\left[\Delta_{t}=j \mid \tilde{U}_{t}, \theta_{2}\right]=\frac{\pi_{j} \times f\left(\tilde{U}_{t} \mid \Delta_{t}=j, \theta_{2}\right)}{f\left(\tilde{U}_{t} \mid \theta_{2}\right)}
$$

where $f\left(\tilde{U} \mid \Delta_{t}=j, \theta_{2}\right)$ is the probability density of the multivariate normal distribution with zero mean and $\Gamma_{j}$ as covariance matrix, evaluated for $\tilde{U}_{t}$.

With equation (35), we compute probabilities at time $t=1$. Then, we compute consecutive probabilities recursively:

$$
P\left[\Delta_{t}=j, \Delta_{t-1}=i \mid \tilde{U}, \theta_{2}\right]=P\left[\Delta_{t-1}=i \mid \tilde{U}, \theta_{2}\right] \times P\left[\Delta_{t}=j \mid \tilde{U}, \theta_{2}\right] \times \pi_{i, j}
$$

where $P\left[\Delta_{t}=j \mid \tilde{U}, \theta_{2}\right]=f\left(\tilde{U} \mid \Delta_{t}=j, \theta_{2}\right)$.

Then, conditional probabilities to be in state $j$ at time $t$ are obtained making the ratio of the sum of the two consecutive probabilities of being in state $j$ at time $t$ and the sum of all consecutive probabilities.

Introduce the notation $\xi_{t \mid \tau}$, the $(N \times 1)$ vector whose $j^{\text {th }}$ element is $P\left[\Delta_{t}=j \mid \tilde{U}_{\tau}, \theta_{2}\right]$. This notation allows to present two cases of $\xi_{t \mid \tau}$ : (i) for $t>\tau$ it represents a forecast about the regime and (ii), for $t<\tau$ it represents the smoothed inference (about the regime in date $t$ based on data obtained through some later date $\tau$ ). We focus on smoothed probabilities that is defined by:

$$
\tilde{\xi}_{t \mid \tau}=\tilde{\xi}_{t \mid t} \odot\left\{\Pi^{\prime} \cdot\left[\tilde{\xi}_{t+1 \mid T}(\div) \tilde{\xi}_{t+1 \mid t}\right]\right\}
$$

Smoothed probabilities are obtained iterating on backward for $t=T, T-1, T-2, \cdots, 1$. We come back from equation (36) to compute consecutive probabilities with smoothed probabilities. Then, we compute $\theta_{2}^{(m)}$ with equation (32) and (33) rescaling at each iteration the correlation matrix with equation (34).

The breaking rule of the algorithm is defined by the fact that the correlation matrix computed 
by the last iteration is almost equal to the previous correlation matrix. We have to define a threshold under which, we consider that matrices are equal.

\section{A.2.3 Initialisation of the Algorithm}

To start the algorithm, we have to choose the space of initial parameters, $\theta_{2}^{(0)}$. In this space, we input correlation matrices for each state of our model (in our case, two). The algorithm starts with one matrix of correlations of the state (1) equal to identity matrix. For the second state, we use the Gramian matrix method (Holmes (1991)) to generate random correlation matrix. Note that a correlation matrix has to be defined semi-positive with diagonal elements that are equal to one and off-diagonal elements that are between -1 and 1 . We use the Gramian matrix $T^{\prime} T$ where $T:=\left(t_{1}, \cdots, t_{K}\right)$ and $t_{i}$ is the $i^{t h}$ column. Then, we normalize the matrix as: $t_{i}=\tau_{i} /\left\|\tau_{i}\right\|$.

For a $\mathrm{K}$-variate process, we generate $\mathrm{K}$ independent pseudo-random vectors normally distributed, $\tau_{i}$. 


\section{B List of Countries}

Table 5 - List of countries in database and available dates. In blue, countries for which the data are available for all markets from the $01 / 01 / 2007$ to the $25 / 02 / 2011$.

\begin{tabular}{rcc} 
& Start & End \\
\hline \hline Argentina & $01 / 06 / 2007$ & $25 / 02 / 2011$ \\
Brazil & $03 / 08 / 2005$ & $25 / 02 / 2011$ \\
Chile & $01 / 09 / 2010$ & $25 / 02 / 2011$ \\
China & $01 / 12 / 2003$ & $25 / 02 / 2011$ \\
Colombia & $29 / 03 / 2004$ & $25 / 02 / 2011$ \\
Czech Republic & $01 / 01 / 2002$ & $25 / 02 / 2011$ \\
Egypt & $02 / 09 / 2009$ & $25 / 02 / 2011$ \\
Hungary & $01 / 01 / 2002$ & $25 / 02 / 2011$ \\
India & $01 / 01 / 2002$ & $25 / 02 / 2011$ \\
Indonesia & $14 / 05 / 2003$ & $25 / 02 / 2011$ \\
Malaysia & $01 / 01 / 2002$ & $25 / 02 / 2011$ \\
Mexico & $01 / 01 / 2002$ & $25 / 02 / 2011$ \\
Peru & $29 / 09 / 2006$ & $25 / 02 / 2011$ \\
Philippines & $01 / 10 / 2010$ & $25 / 02 / 2011$ \\
Poland & $11 / 02 / 2002$ & $25 / 02 / 2011$ \\
Russia & $03 / 01 / 2005$ & $25 / 02 / 2011$ \\
Slovakia & $06 / 10 / 2004$ & $31 / 12 / 2008$ \\
South Africa & $01 / 01 / 2002$ & $25 / 02 / 2011$ \\
Thailand & $04 / 01 / 2005$ & $25 / 02 / 2011$ \\
Turkey & $24 / 08 / 2005$ & $25 / 02 / 2011$ \\
\hline
\end{tabular}

